\title{
Recurrent Malignant Central Nervous System Neoplasm
}

National Cancer Institute

\section{Source}

National Cancer Institute. Recurrent Malignant Central Nervous System Neoplasm. NCI

Thesaurus. Code C153823.

The reemergence of a malignant central nervous system neoplasm after a period of remission. 